\title{
Influence of isotretinoin on hippocampal-based learning in human subjects
}

\author{
Anthony D. Ormerod • Chamandeep K. Thind • \\ Shantini A. Rice • Ian C. Reid • Justin H. G. Williams • \\ Peter J. A. McCaffery
}

Received: 23 September 2011 / Accepted: 5 December 2011 /Published online: 24 December 2011

(C) The Author(s) 2011. This article is published with open access at Springerlink.com

\begin{abstract}
Rationale The acne drug isotretinoin has 13-cis retinoic acid as its active agent. Adverse effects that have been described include severe depression. Animal studies indicate that the hippocampus is particularly sensitive to retinoic acid. Changes induced by isotretinoin to hippocampal function could contribute to depression but may be more evident in altered visuospatial learning and memory, the primary function of the hippocampus.

Objectives We aimed to test the hypothesis that a course of oral isotretinoin therapy would result in declining visuospatial learning and memory.

Methods CANTAB tasks designed to assess visuospatial memory were performed repeatedly on 14 males and 3 females in an open prospective observational study of patients with severe acne undergoing isotretinoin therapy. Beck's Depression Inventory and Global Acne Grade were also administered.
\end{abstract}

Justin H. G. Williams and Peter J. A. McCaffery are joint senior authors.

A. D. Ormerod $(\bowtie)$

Division of Applied Medicine, University of Aberdeen,

Polwarth Building, Foresterhill,

Aberdeen AB25 2ZN, UK

e-mail: a.d.ormerod@abdn.ac.uk

I. C. Reid · J. H. G. Williams

Department of Psychiatry, University of Aberdeen,

Aberdeen, UK

P. J. A. McCaffery

Institute of Medical Sciences, University of Aberdeen,

Aberdeen, UK

C. K. Thind $\cdot$ S. A. Rice

Department of Dermatology, Aberdeen Royal Infirmary,

Aberdeen, UK
Results Performance stayed unchanged for DMS, SRM and PRM tasks, while surprisingly participants improved their speed on the PRM task. Performance improved across sessions on the PAL task, and moreover the dose of isotretinoin correlated with improvement in the total trial score, reduction in total error rate and stage completed at the first trial. Conclusion Isotretinoin does not reduce learning and memory and our study suggests that it may instead lead to a doserelated improvement in specific aspects of hippocampal learning and memory. Retinoic acid functions in the hippocampus as the active metabolite of vitamin A, suggesting that this may be a limiting factor in the human hippocampus and addition of exogenous retinoic acid brings levels closer to an optimal state.

Keywords Isotretinoin · Retinoic acid · Memory · Learning · Hippocampus · CANTAB

\section{Introduction}

Isotretinoin (13-cis retinoic acid, 13-cis RA) has been an effective treatment for acne since its introduction in 1982. This drug acts to suppress acne in multiple ways, reducing sebaceous gland secretion and size, possibly by inhibiting proliferation and inducing apoptosis of sebocytes (Nelson et al. 2006) and also acting as an anti-inflammatory agent blocking the migration of polymorphonuclear leukocytes into the skin (Wozel et al. 1991). It is believed to act by isomerisation to all-trans-RA in tissues (Shih et al. 1986; Tsukada et al. 2000), which then activates specific receptors for retinoic acid (Nelson et al. 2009; Rochette-Egly and Germain 2009). The RA receptors are members of the nuclear receptor family regulating the transcription of several hundreds of genes (Balmer and Blomhoff 2002) and 
isotretinoin temporally regulates distinct sets of genes in a patient's skin (Nelson et al. 2009).

Retinoic acid is synthesized endogenously from vitamin $\mathrm{A}$ and acts to regulate cell proliferation and differentiation in almost all organ systems of the body including bone, cardiovascular, immune, reproductive and excretory systems (Sporn et al. 1994). The nervous system is also a target and how local synthesis of RA regulates the patterning of gene expression during central nervous system (CNS) development has been extensively studied (McCaffery et al. 2003). However, less is known regarding its action in the adult CNS (Bremner and McCaffery 2008).

The hippocampus is one of the few regions in which RA signaling is maintained through both embryonic development and into adulthood (Misner et al. 2001). The hippocampus is essential for the generation of episodic and spatial memory, processes dependent on the RA-regulated functions of neuronal plasticity, long-term potentiation (LTP) and neurogenesis (McCaffery et al. 2006). Deficiency in RA created by depletion of its substrate vitamin A leads to a reduction in the ability of rats to perform in the hippocampal-dependent radial maze task and loss of LTP (Misner et al. 2001) (Cocco et al. 2002), while similarly null mutation of RA receptors results in loss of both LTP and long-term depression (LTD) as well as deficits in spatial learning tasks (Chiang et al. 1998). An alternative mechanism to LTP-regulating synaptic strength and plasticity, known as synaptic scaling, is also regulated by RA, although via a mechanism that does not involve transcriptional regulation (Aoto et al. 2008) and likely requires translational control (Poon and Chen 2008). RA is also required for neurogenesis in the hippocampus, inducing the expression of neurotrophin receptors (Takahashi et al. 1999) and promoting neuronal differentiation and cell survival (Jacobs et al. 2006).

The negative effects of RA on learning and memory in the rodent follow a U-curve shape, whereby RA deficiency results in a decline in learning and memory and excess similarly impairs these behaviours in both mouse (Crandall et al. 2004) and rat (Dopheide and Morgan 2008). This may reflect a function for RA in regulating neuronal plasticity that relies on a patterned RA distribution, as occurs in the embryonic CNS. Such patterns are highly sensitive to abnormally high or low RA (McCaffery et al. 2003).

These important effects of RA in rodents suggest that high doses of RA may affect human brain function. In humans, high doses of RA are given in the form of isotretinoin (13-cis retinoic acid), a retinoid highly effective in acne therapy. In clinical practice, there is mounting evidence strongly suggesting a link between isotretinoin therapy and psychopathology (Kontaxakis et al. 2009), although the possible link with depression and suicide (Sundstrom et al. 2010) has been difficult to separate from the psychosocial effects of severe acne (Halvorsen et al. 2011). The most frequent CNS adverse effect is headache (Bremner and McCaffery 2008) and many reports have identified idiosyncratic adverse events that include increases in anxiety, aggression and depression (Bremner et al. 2011; Bremner and McCaffery 2008). Mood change is one of the most important considerations in clinical practice (Goodfield et al. 2010).

The effects of isotretinoin on mood and behaviour might result from altered hippocampal function. Studies in animals have shown that treatment with 13-cis RA results in a reduction in hippocampal neurogenesis, a fall in performance in learning and memory tasks (Crandall et al. 2004) as well as a decline in the size of the hippocampus (McCaffery et al. 2006). Reduction in hippocampal size may be a key anatomical change in the brain linked to depressive disorder and possibly associated with accompanying deterioration in memory (Dere et al. 2010; Fairhall et al. 2010; MacQueen and Frodl 2011). We therefore investigated the influence of isotretinoin on human learning and memory.

\section{Materials and methods}

\section{Aims}

The aims of this study were (a) to test the hypothesis that a course of oral isotretinoin therapy would result in decline in learning and memory as measured using the CANTAB cognitive testing battery, (b) to generate data to inform a larger study regarding sample size, test procedures and outcome measures and (c) to identify cognitive tasks to be used in future functional imaging studies.

\section{Patients and methods}

This was an open prospective observational study. As it was not considered ethical to withhold effective treatment for patients with severe acne, we adopted an open design with each subject baseline test providing the baseline for a withinsubjects comparison. In a small study, variation between subjects can be high and matching controls for IQ, severity of acne and depression would require a much larger study. The study was approved by the North Scotland Research Ethics committee and conducted between 2008 and 2010.

\section{Participants}

We invited patients who were attending a dermatology outpatient clinic for treatment of severe acne vulgaris, aged 16 or over, in whom a clinical decision had been made to treat with isotretinoin to participate. We excluded patients with intelligence below normal who would not be able to understand the CANTAB psychometric tests, subjects with neurological disease, epilepsy or pre-existing mental health problems, pregnant females, females not taking contraceptive precautions 
and patients taking Dianette ${ }^{\circledR}$, sedative or psycho-active medication.

\section{Intervention}

Patients were treated with isotretinoin, $0.5-1 \mathrm{mg} / \mathrm{kg} / \mathrm{day}$, for 3-6 months until satisfactory clearance of acne lesions was achieved. CANTAB visuospatial memory tasks, Beck's Depression Inventory (BDI) and Global Acne Grade (GAG) were assessed on three separate visits: the first immediately prior to starting isotretinoin, the second at 3 months later during isotretinoin therapy and with the final visit at 2 months after stopping therapy.

\section{Procedure}

We studied a limited range of cognitive tests to avoid tiring the subject and to keep testing under $1 \mathrm{~h}$. If subjects were tired, they were permitted to take a break. The following CANTAB tests were performed in parallel mode and are summarized in Table 1: motor screening was designed to relax the subject and introduce them to the touch screen and was given at the start of each session, delayed matching to sample (DMS) paired associate learning (PAL), pattern recognition memory (PRM) and spatial recognition memory (SRM).

At each visit, we recorded the dose of isotretinoin $(\mathrm{mg} / \mathrm{kg})$, any perceived subjective side effects, acne severity rated by the GAGs score and depression using the Becks inventory.

\section{Sample size}

Based on a clinically meaningful change of $20 \%$ on a primary outcome measure and one-sided significance alpha $=0.025$, we assumed a standard deviation of $20 \%$ in the primary outcome and had a $95 \%$ power of detecting this change with 18 patients.

\section{Statistics}

Statistics were performed using PASW statistics 18 . Withinsubject comparisons were made using repeated-measures ANOVA. Pearson's coefficient was used to examine correlations.

\section{Results}

Participants

Data were collected from 16 participants who were tested before, during and after treatment with isotretinoin and a further one who was lost to the study after treatment was completed. There were many more male than female participants (ratio of about 3:1) and the males were both significantly younger and had more severe acne. Both groups were prescribed similar doses of isotretinoin of about $0.5 \mathrm{mg} / \mathrm{kg} /$ day (Table 2).

\section{Depression}

We first looked at whether depression, as measured by the BDI, changed during treatment. In a paired $t$-test, there were non-significant trends towards an increased BDI score with treatment (mean [SD] before $=3.76$ [3.36], mean during [SD] $=5.76$ [4.19], $p=0.071)$. We also looked at whether the size of dose correlated with change in BDI score. This revealed a trend towards an effect with higher dose associated with a larger change in BDI $(r=0.454, p=0.067, n=17)$.

\section{Memory}

The effects of treatment on memory performance are shown in Tables 3 and 4 and Fig. 1. A univariate repeated-measures ANOVA showed that performance stayed unchanged for DMS, SRM and PRM, though participants improved their speed on the PRM task. However, performance improved across sessions on the PAL task. Inclusion of either the BDI baseline depression score or its amount of change as a covariate did not alter the findings.

Relationships with dose of isotretinoin

Dose of isotretinoin correlated with improvement in the total trial score $(r=0.541, p=0.025)$, reduction in total error rate $(r=0.485, p=0.049)$ (Fig. 2$)$ and stage completed at the first trial $(r=0.523, p=0.031)$ as percentage change from baseline. There was no significant correlation between dose and percent improvement in first trial memory score $(r=0.366$, $p=0.148)$ and average latency improvement $(r=0.027, p=$ $0.917)$.

\section{Discussion}

Numerous behavioural studies in animal models have pointed to behavioural changes in rodents when the balance of RA is disrupted, either from exposure to excess or deficiency, as previously reviewed (Bremner et al. 2011; Olson and Mello 2010). These results indicate that a balance of RA in the brain must be maintained and that either too much or too little is detrimental. This study is the first to be performed to objectively determine possible alterations in learning and memory with isotretinoin treatment using a CANTAB cognitive 


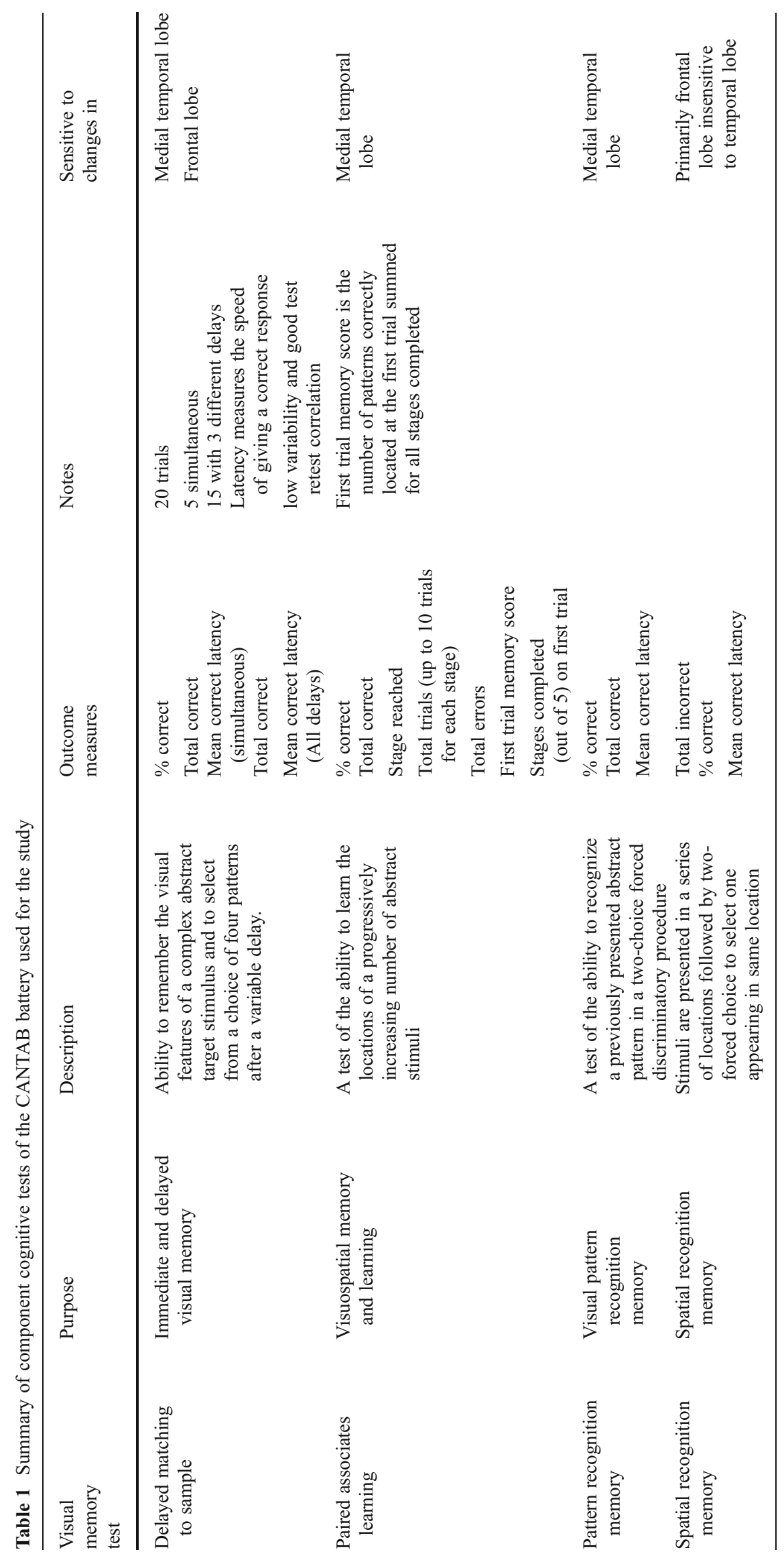


Table 2 Summary of participant characteristics

\begin{tabular}{|c|c|c|c|c|c|c|c|}
\hline & & $\begin{array}{l}\text { Age } \\
\text { (years) }\end{array}$ & $\begin{array}{l}\text { Weight } \\
(\mathrm{kg})\end{array}$ & $\begin{array}{l}\text { GAGS } \\
\text { (baseline) }\end{array}$ & $\begin{array}{l}\text { Becks depression } \\
\text { inventory (baseline) }\end{array}$ & $\begin{array}{l}\text { Initial dose } \\
(\mathrm{mg} / \mathrm{kg})\end{array}$ & $\begin{array}{l}\text { Midtreatment } \\
\text { dose }(\mathrm{mg} / \mathrm{kg})\end{array}$ \\
\hline \multirow[t]{2}{*}{ Males, $n=13$} & Mean (SD) & $20.62(4.31)$ & $78.54(14.74)$ & $31.00(5.29)$ & $3.62(3.69)$ & $0.46(0.13)$ & $0.62(0.26)$ \\
\hline & Range & $15-28$ & $60-120$ & $21-40$ & $0-11$ & $0.12-0.60$ & $0.17-1.04$ \\
\hline \multirow[t]{2}{*}{ Females, $\mathrm{n}=4$} & Mean (SD) & $27.75(3.95)$ & $63.50(7.19)$ & $21.00(2.36)$ & $4.25(3.74)$ & $0.53(0.06)$ & $0.63(0.21)$ \\
\hline & Range & $22-31$ & $53-69$ & $16-25$ & $1-6$ & $0.46-0.60$ & $0.45-0.87$ \\
\hline \multirow[t]{2}{*}{ Total, $\mathrm{n}=17$} & Mean (SD) & $22.29(5.15)$ & $75.0(14.69)$ & $28.65(6.54)$ & $3.76(3.36)$ & $0.48(0.12)$ & $0.62(0.24)$ \\
\hline & Range & $15-31$ & $53-120$ & $16-40$ & $0-11$ & $0.12-0.60$ & $0.17-1.04$ \\
\hline$t, p$ & & $3.09,0.024$ & $2.76,0.018$ & $7.51,0.004$ & $0.635, \mathrm{NS}$ & $0.069, \mathrm{NS}$ & $0.016, \mathrm{NS}$ \\
\hline
\end{tabular}

assessment system that employs a succession of neuropsychological tests performed on a touch screen computer.

The CANTAB tests were focused on hippocampal-based learning and the study was designed with the hypothesis that isotretinoin treatment for acne would have a negative influence on learning and memory, comparing the effect of the drug on individuals before, during and after treatment. From this comparison, no significant decline was evident in any of the outcome measures for DMS, SRM and PRM although several test outcomes were relatively insensitive to a measure of improvement because all groups scored a high percentage of correct response even though there was a trend towards worsening of the self-rated depression score, and depression can affect memory and learning. It may be concluded that isotretinoin does not reduce learning and memory and our hypothesis was negated.

Remarkable, however, was the contrary finding that memory significantly improved with treatment. This was the case for the outcome measures of the PAL test and the reaction times on the PRM task. However, before we can conclude that isotretinoin improves memory, consideration needs to be given to the possibility that this is a practice effect, stemming simply from repeated performance of the test, or a placebo effect since this study was run as an open trial. Indeed the results of a recent study support our findings of improved learning performance with isotretinoin treatment (Ergun et al. 2011), but their methods were unable to distinguish this from practice effects. In this new study, practice effects are unlikely to account for the observed improvement in paired associate learning for two reasons: first, the effect is specific to only one subdomain of cognitive function - other assessments do not show improvement over time, and second, each administration of the PAL uses trial-unique (fresh) cues. Furthermore, these tests were conducted at intervals that were separated by 2 and 3 months at a time and parallel versions were used. It would therefore seem unlikely that participants could benefit much from earlier experience and previous studies have not found benefits of repetition.

Fowler et al. (2002) did not find any change in PAL performance among typical controls when repeating testing five times over a period of 2 years, though participants with early dementia exhibited deterioration which was not evident on standard memory tests. Lowe and Rabbit report no change between trials separated 4 weeks apart on the PAL task (Lowe and Rabbitt 1998). Furthermore, in separate studies, Porter et

Table 3 Effects of treatment on memory tests

\begin{tabular}{|c|c|c|c|c|c|c|c|c|c|c|c|c|}
\hline & \multicolumn{3}{|c|}{ Before treatment } & \multicolumn{3}{|c|}{ During treatment } & \multicolumn{3}{|c|}{ After treatment } & \multicolumn{3}{|c|}{$\begin{array}{l}\text { Univariate repeated-measures } \\
\text { ANOVA }(n=16)\end{array}$} \\
\hline & Mean & SD & Range & Mean & SD & Range & Mean & SD & Range & $\mathrm{df}$ & $F$ & $P^{\mathrm{a}}$ \\
\hline DMS total correct (all delays) & 13.59 & 1.278 & $11-15$ & 13.18 & 1.380 & $9-15$ & 13.44 & 1.209 & $10-15$ & 1.978 & 1.383 & 0.266 \\
\hline SRM percent correct & 81.18 & 13.75 & $45-100$ & 82.65 & 11.74 & $65-100$ & 83.13 & 10.94 & $60-100$ & 1.745 & .241 & 0.757 \\
\hline PRM percent correct & 90.93 & 10.02 & $71-100$ & 94.11 & 5.32 & $83-100$ & 91.93 & 8.40 & $79-100$ & 1.962 & .029 & 0.969 \\
\hline PAL first trial memory score & 15.59 & 2.32 & $12-19$ & 17.24 & 2.562 & $13-21$ & 18.13 & 2.13 & $14-21$ & 1.657 & 9.065 & 0.002 \\
\hline PAL stages completed on first trial & 3.59 & 0.51 & $3-4$ & 3.47 & .717 & $2-5$ & 3.88 & 0.62 & $3-5$ & 1.981 & 3.296 & 0.051 \\
\hline PAL total errors & 13.29 & 13.49 & $2-61$ & 5.82 & 4.305 & $0-15$ & 4.50 & 4.59 & $0-16$ & 1.240 & 7.774 & 0.009 \\
\hline PAL total trials & 8.76 & 2.66 & $6-17$ & 7.41 & 1.417 & $5-11$ & 6.81 & 1.42 & $5-10$ & 1.420 & 7.296 & 0.008 \\
\hline
\end{tabular}

$D M S$ delayed matching to sample, $S R M$ spatial recognition memory, $P R M$ pattern recognition memory, $P A L$ paired associate learning

${ }^{\text {a }}$ Greenhouse-Geiser correction 
Table 4 Effects of treatment on reaction times (mean correct latency)

\begin{tabular}{llllllllllllllllllll}
\hline & $\begin{array}{l}\text { Mean } \\
\text { baseline }\end{array}$ & SD & Minimum & Maximum & $\begin{array}{l}\text { Mean } \\
\text { during } \\
\text { treatment }\end{array}$ & SD & Minimum & Maximum & $\begin{array}{l}\text { Mean } \\
\text { after } \\
\text { treatment }\end{array}$ & SD & Minimum Maximum df & $F$ & $P^{\text {a }}$ \\
\hline $\begin{array}{c}\text { DMS mean correct } \\
\text { latency (all delays) }\end{array}$ & 3,079 & 834 & 1,759 & 5,121 & 2,697 & 712 & 1,163 & 3,799 & 2,723 & 816 & 1,327 & 3,963 & 1.963 & 2.675 & .087 \\
$\begin{array}{c}\text { SRM mean correct } \\
\text { latency }\end{array}$ & 2,002 & 514 & 1,135 & 3,062 & 1,828 & 333 & 1,130 & 2,595 & 1,735 & 399 & 925 & 2,300 & 1.904 & 2.217 & .130 \\
$\begin{array}{c}\text { PRM mean correct } \\
\text { latency }\end{array}$ & 1,894 & 455 & 1,142 & 2,873 & 1,731 & 304 & 1,301 & 2,293 & 1,536 & 272 & 1,154 & 2,028 & 1.880 & 5.759 & .009 \\
$\begin{array}{c}\text { Mean overall correct } \\
\text { latency }\end{array}$ & 2,409 & 558 & 1,479 & 3,614 & 2,187 & 436 & 1,432 & 2,962 & 2,064 & 408 & 1,187 & 2,654 & & \\
\hline
\end{tabular}

${ }^{\text {a }}$ Greenhouse-Geiser correction, univariate repeated-measures ANOVA

al., in a group of older people, and Falconer et al., in depressed patients receiving electroconvulsive therapy ECT, also found no difference in PAL as a result of repeated testing (Falconer et al. 2010; Porter et al. 2002).

A further indication of the direct effect of isotretinoin on learning and memory could be determined by analysis of

a

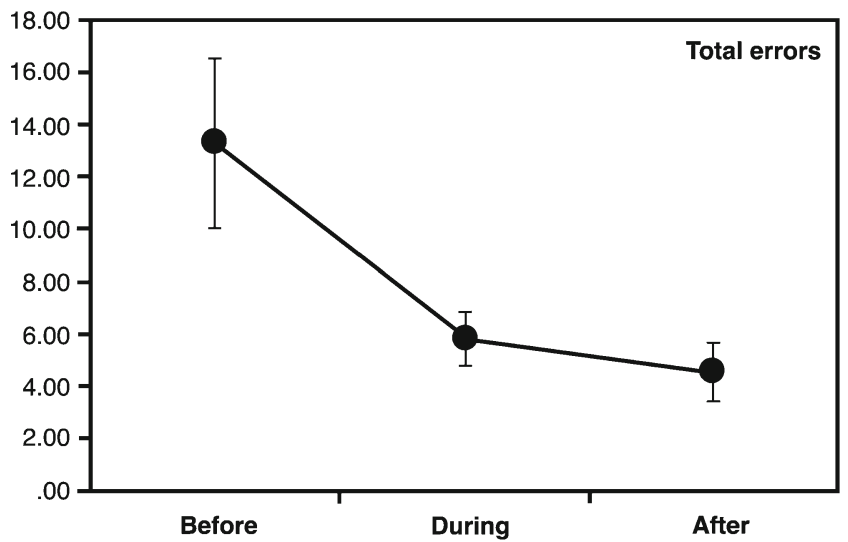

b

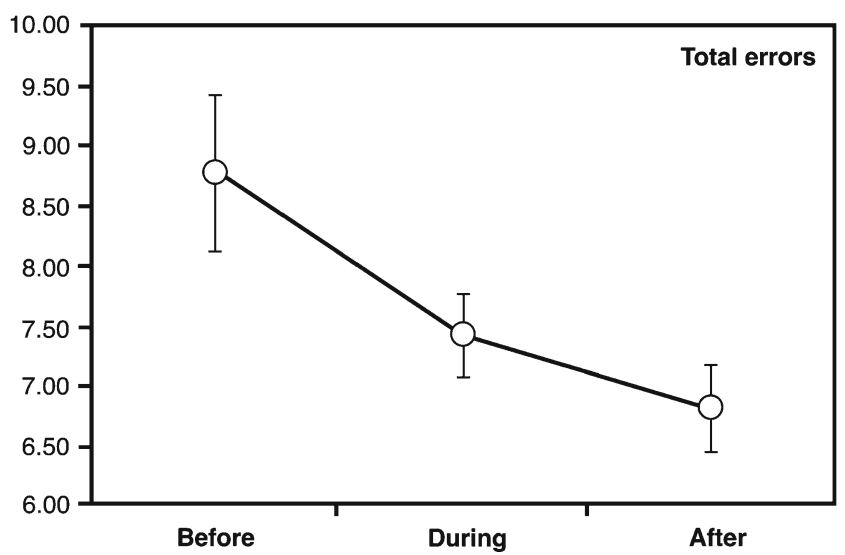

Fig. 1 Effect of isotretinoin treatment on memory scores in the paired associated learning task showing: a total errors significantly reduced $(p=0.009), \mathbf{b}$ total trials significantly reduced $(p=0.008)$ correlation with the dose of isotretinoin. We therefore looked at whether improvements in performance on memory tasks correlated with dose of isotretinoin given during the main period of treatment. The improvement in performance in PAL showed a significant positive correlation with the maintenance dose measured in milligrams per kilogram. Such a correlation cannot be explained by either practice or placebo effects alone since the participants were not aware of their dose.

Why might isotretinoin have an enduring positive influence on learning? All-trans RA, to which 13-cis RA can be isomerized in vivo (Shih et al. 1986; Tsukada et al. 2000), is essential for neuronal plasticity - the capacity of individual neurons, their connections and neural circuits to adapt to a change in environment as well as form new memories. The most studied aspect of this process lies at the level of single synapses and weakens or strengthens their capacity to transmit information

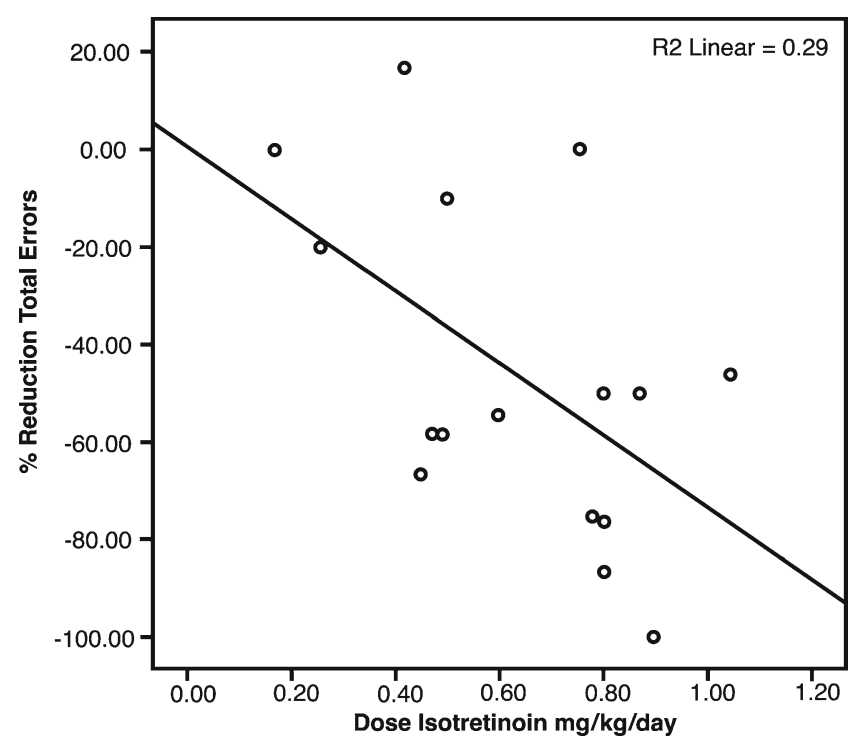

Fig. 2 Scatterplot showing improvements in performance on paired associated learning task as an effect of treatment with isotretinoin showing that the reduction in errors in PAL is correlated with the dose of isotretinoin $(r=0.485, p=0.049)$ 
from neuron to neuron to either facilitate or weaken particular circuits to form or degrade memories. Evidence from studies in rodents has indicated that loss of RA or block of RA signaling via mutation of the receptor results in dramatic loss of such Hebbian plasticity, specifically through failure of LTP and also degradation of LTD (Chiang et al. 1998; Cocco et al. 2002; McCaffery et al. 2006; Misner et al. 2001). Recently, RA has been found to be involved in another form of neuronal plasticity. It was recognized that Hebbian plasticity such as LTP includes positive feedback and progressively increases its own activity. Homeostatic systems are necessary to dampen the results of such positive feedback known as homeostatic synaptic plasticity (Pozo and Goda 2010). The RA signaling system provides one route for such homeostasis by direct regulation of glutamate receptors (Aoto et al. 2008; Poon and Chen 2008). Given that the results of this study imply that isotretinoin has a positive influence on learning and memory, this suggests that RA signaling in the human brain is suboptimal and can be improved by application of additional RA. This differs from, for instance, mouse (Crandall et al. 2004) or rat (Dopheide and Morgan 2008) in which application of isotretinoin, at a similar dose per body weight as used for humans, pushes RA signaling beyond the optimal point, leading to a decline in capacity to perform memory tasks. The reason for suboptimal levels in the human brain is unknown but if, as proposed, RA for the hippocampus derives from the surrounding meninges (Sakai et al. 2004), then the size of the human hippocampus may limit the amount of RA reaching hippocampal neurons.

This study also points to an enduring effect of RA on human learning and memory. A third aspect of neural plasticity that may lead to longer-lasting effects of isotretinoin is hippocampal neurogenesis - the birth of new granule neurons in the dentate gyrus. The process is regulated by a number of factors including RA (Jacobs et al. 2006; Takahashi et al. 1999). Neurogenesis and incorporation of new neurons into hippocampal circuitry promotes several aspects of hippocampal-dependent memory or improves pattern separation, while inhibition of this process blocks spatial and object recognition memory and contextual fear conditioning (Imayoshi et al. 2008; Jessberger et al. 2009; Sahay et al. 2011; Saxe et al. 2006). Given that RA is required for neuronal differentiation and cell survival of granule neurons in the dentate gyrus, if isotretinoin promotes this process in the human hippocampus, then the increased number of new granule neurons would lead to long-lasting effects to promote learning and memory. It should be noted though that not all aspects of hippocampalbased spatial memory require neurogenesis and working memory required for a spatial task in mice has shown to be improved by inhibition of neurogenesis (Saxe et al. 2007). It may be further noted that, in mouse, isotretinoin has been reported to inhibit neurogenesis (Crandall et al. 2004).
This study found only moderate influence of isotretinon to improve learning and memory in a dose-dependent manner. This may be because the levels of retinoid signaling in the young adult in this study were only marginally suboptimal. This may not be the case, however, in older adults.

Studies in aged mice (21-23 months old) have found that the levels of brain RA receptors are lower than in younger animals. However, this can be reversed by the treatment of mice with RA, entirely reversing the decline in hippocampaldependent memory in animals and restoring LTP in CA3 of the hippocampus (Enderlin et al. 1997; Etchamendy et al. 2001). Low levels of RA signaling may occur in Alzheimer's disease (Corcoran et al. 2004; Goodman and Pardee 2003) and application of RA to a transgenic animal model of Alzheimer's disease leads to improved learning and spatial memory (Ding et al. 2008). It may be the case that the effects of isotretinoin to improve learning and memory in young adults may be far more marked in the elderly where RA signaling may be deficient. This may provide a promising future line of research.

Acknowledgement We would like to thank the following for assistance in this study: Lee S Boag, Janusz Andrzej Mazanowski and Linda G. Lawson.

Disclosure/conflicts of interest The authors have no financial or other conflicts of interest pertinent to the subject of this paper.

Open Access This article is distributed under the terms of the Creative Commons Attribution Noncommercial License which permits any noncommercial use, distribution, and reproduction in any medium, provided the original author(s) and source are credited.

\section{References}

Aoto J, Nam CI, Poon MM, Ting P, Chen L (2008) Synaptic signaling by all-trans retinoic acid in homeostatic synaptic plasticity. Neuron 60:308-320

Balmer JE, Blomhoff R (2002) Gene expression regulation by retinoic acid. J Lipid Res 43:1773-1808

Bremner JD, McCaffery P (2008) The neurobiology of retinoic acid in affective disorders. Prog Neuropsychopharmacol Biol Psychiatry 32:315-331

Bremner JD, Shearer KD, McCaffery PJ (2011) Retinoic acid and affective disorders: the evidence for an association. J Clin Psychiatry. doi:10.4088/JCP.10r05993

Chiang MY, Misner D, Kempermann G, Schikorski T, Giguere V, Sucov HM, Gage FH, Stevens CF, Evans RM (1998) An essential role for retinoid receptors RARbeta and RXRgamma in long-term potentiation and depression. Neuron 21:1353-1361

Cocco S, Diaz G, Stancampiano R, Diana A, Carta M, Curreli R, Sarais L, Fadda F (2002) Vitamin A deficiency produces spatial learning and memory impairment in rats. Neuroscience 115:475-482

Corcoran JP, So PL, Maden M (2004) Disruption of the retinoid signalling pathway causes a deposition of amyloid beta in the adult rat brain. Eur J Neurosci 20:896-902

Crandall J, Sakai Y, Zhang J, Koul O, Mineur Y, Crusio WE, McCaffery P (2004) 13-cis-Retinoic acid suppresses hippocampal cell division 
and hippocampal-dependent learning in mice. Proc Natl Acad Sci U S A 101:5111-5116

Dere E, Pause BM, Pietrowsky R (2010) Emotion and episodic memory in neuropsychiatric disorders. Behav Brain Res 215:162-171

Ding Y, Qiao A, Wang Z, Goodwin JS, Lee ES, Block ML, Allsbrook M, McDonald MP, Fan GH (2008) Retinoic acid attenuates betaamyloid deposition and rescues memory deficits in an Alzheimer's disease transgenic mouse model. J Neurosci 28:11622-11634

Dopheide MM, Morgan RE (2008) Isotretinoin (13-cis-retinoic acid) alters learning and memory, but not anxiety-like behavior, in the adult rat. Pharmacol Biochem Behav 91:243-251

Enderlin V, Pallet V, Alfos S, Dargelos E, Jaffard R, Garcin H, Higueret P (1997) Age-related decreases in mRNA for brain nuclear receptors and target genes are reversed by retinoic acid treatment. Neurosci Lett 229:125-129

Ergun T, Seckin D, Ozaydin N, Bakar O, Comert A, Atsu N, Demircay Z, Yoney H, Zaimoglu S (2011) Isotretinoin has no negative effect on attention, executive function and mood. J Eur Acad Dermatol Venereol. doi:10.1111/j.1468-3083.2011.04089.x

Etchamendy N, Enderlin V, Marighetto A, Vouimba RM, Pallet V, Jaffard R, Higueret P (2001) Alleviation of a selective age-related relational memory deficit in mice by pharmacologically induced normalization of brain retinoid signaling. J Neurosci 21:6423-6429

Fairhall SL, Sharma S, Magnusson J, Murphy B (2010) Memory related dysregulation of hippocampal function in major depressive disorder. Biol Psychol 85:499-503

Falconer DW, Cleland J, Fielding S, Reid IC (2010) Using the Cambridge Neuropsychological Test Automated Battery (CANTAB) to assess the cognitive impact of electroconvulsive therapy on visual and visuospatial memory. Psychol Med 40:1017-1025

Fowler KS, Saling MM, Conway EL, Semple JM, Louis WJ (2002) Paired associate performance in the early detection of DAT. J Int Neuropsychol Soc 8:58-71

Goodfield MJ, Cox NH, Bowser A, McMillan JC, Millard LG, Simpson NB, Ormerod AD (2010) Advice on the safe introduction and continued use of isotretinoin in acne in the U.K. Br J Dermatol 162:1172-1179

Goodman AB, Pardee AB (2003) Evidence for defective retinoid transport and function in late onset Alzheimer's disease. Proc Natl Acad Sci U S A 100:2901-2905

Halvorsen JA, Stern RS, Dalgard F, Thoresen M, Bjertness E, Lien L (2011) Suicidal ideation, mental health problems, and social impairment are increased in adolescents with acne: a populationbased study. J Invest Dermatol 131:363-370

Imayoshi I, Sakamoto M, Ohtsuka T, Takao K, Miyakawa T, Yamaguchi M, Mori K, Ikeda T, Itohara S, Kageyama R (2008) Roles of continuous neurogenesis in the structural and functional integrity of the adult forebrain. Nat Neurosci 11:1153-1161

Jacobs S, Lie DC, Decicco KL, Shi Y, Deluca LM, Gage FH, Evans RM (2006) Retinoic acid is required early during adult neurogenesis in the dentate gyrus. Proc Natl Acad Sci U S A 103:3902-3907

Jessberger S, Clark RE, Broadbent NJ, Clemenson GD Jr, Consiglio A, Lie DC, Squire LR, Gage FH (2009) Dentate gyrus-specific knockdown of adult neurogenesis impairs spatial and object recognition memory in adult rats. Learn Mem 16:147-154

Kontaxakis VP, Skourides D, Ferentinos P, Havaki-Kontaxaki BJ, Papadimitriou GN (2009) Isotretinoin and psychopathology: a review. Ann Gen Psychiatry 8:2

Lowe C, Rabbitt P (1998) Test/re-test reliability of the CANTAB and ISPOCD neuropsychological batteries: theoretical and practical issues. Cambridge neuropsychological test automated battery. International study of post-operative cognitive dysfunction. Neuropsychologia 36:915-923

MacQueen G, Frodl T (2011) The hippocampus in major depression: evidence for the convergence of the bench and bedside in psychiatric research? Mol Psychiatry 16:252-264
McCaffery PJ, Adams J, Maden M, Rosa-Molinar E (2003) Too much of a good thing: retinoic acid as an endogenous regulator of neural differentiation and exogenous teratogen. Eur J Neurosci 18:457-472

McCaffery P, Zhang J, Crandall JE (2006) Retinoic acid signaling and function in the adult hippocampus. J Neurobiol 66:780-791

Misner DL, Jacobs S, Shimizu Y, de Urquiza AM, Solomin L, Perlmann T, De Luca LM, Stevens CF, Evans RM (2001) Vitamin A deprivation results in reversible loss of hippocampal long-term synaptic plasticity. Proc Natl Acad Sci U S A 98:11714-11719

Nelson AM, Gilliland KL, Cong Z, Thiboutot DM (2006) 13-cis Retinoic acid induces apoptosis and cell cycle arrest in human SEB-1 sebocytes. J Invest Dermatol 126:2178-2189

Nelson AM, Zhao W, Gilliland KL, Zaenglein AL, Liu W, Thiboutot DM (2009) Temporal changes in gene expression in the skin of patients treated with isotretinoin provide insight into its mechanism of action. Dermatoendocrinol 1:177-187

Olson CR, Mello CV (2010) Significance of vitamin A to brain function, behavior and learning. Mol Nutr Food Res 54:489-495

Poon MM, Chen L (2008) Retinoic acid-gated sequence-specific translational control by RARalpha. Proc Natl Acad Sci U S A 105:20303-20308

Porter RJ, Barnett NA, Idey A, McGuckin EA, O'Brien JT (2002) Effects of hydrocortisone administration on cognitive function in the elderly. J Psychopharmacol 16:65-71

Pozo K, Goda Y (2010) Unraveling mechanisms of homeostatic synaptic plasticity. Neuron 66:337-351

Rochette-Egly C, Germain P (2009) Dynamic and combinatorial control of gene expression by nuclear retinoic acid receptors (RARs). Nucl Recept Signal 7:e05

Sahay A, Scobie KN, Hill AS, O'Carroll CM, Kheirbek MA, Burghardt NS, Fenton AA, Dranovsky A, Hen R (2011) Increasing adult hippocampal neurogenesis is sufficient to improve pattern separation. Nature 472:466-470

Sakai Y, Crandall JE, Brodsky J, McCaffery P (2004) 13-cis Retinoic acid (accutane) suppresses hippocampal cell survival in mice. Ann N Y Acad Sci 1021:436-440

Saxe MD, Battaglia F, Wang JW, Malleret G, David DJ, Monckton JE, Garcia AD, Sofroniew MV, Kandel ER, Santarelli L, Hen R, Drew MR (2006) Ablation of hippocampal neurogenesis impairs contextual fear conditioning and synaptic plasticity in the dentate gyrus. Proc Natl Acad Sci U S A 103:17501-17506

Saxe MD, Malleret G, Vronskaya S, Mendez I, Garcia AD, Sofroniew MV, Kandel ER, Hen R (2007) Paradoxical influence of hippocampal neurogenesis on working memory. Proc Natl Acad Sci U S A 104:4642-4646

Shih TW, Shealy YF, Strother DL, Hill DL (1986) Nonenzymatic isomerization of all-trans- and 13-cis-retinoids catalyzed by sulfhydryl groups. Drug Metab Dispos 14:698-702

Sporn MB, Roberts AB, Goodman DS (1994) The retinoids: biology, chemistry, and medicine, 2nd edn. Raven, New York

Sundstrom A, Alfredsson L, Sjolin-Forsberg G, Gerden B, Bergman U, Jokinen J (2010) Association of suicide attempts with acne and treatment with isotretinoin: retrospective Swedish cohort study. BMJ 341:c5812

Takahashi J, Palmer TD, Gage FH (1999) Retinoic acid and neurotrophins collaborate to regulate neurogenesis in adult-derived neural stem cell cultures. J Neurobiol 38:65-81

Tsukada M, Schroder M, Roos TC, Chandraratna RA, Reichert U, Merk HF, Orfanos CE, Zouboulis CC (2000) 13-cis Retinoic acid exerts its specific activity on human sebocytes through selective intracellular isomerization to all-trans retinoic acid and binding to retinoid acid receptors. J Invest Dermatol 115:321-327

Wozel G, Chang A, Zultak M, Czarnetzki BM, Happle R, Barth J, van de Kerkhof PC (1991) The effect of topical retinoids on the leukotriene-B4-induced migration of polymorphonuclear leukocytes into human skin. Arch Dermatol Res 283:158-161 